\title{
Study of InN nanorods growth mechanism using ultrathin Au layer by plasma-assisted MBE on Si(111)
}

\author{
Mahesh Kumar • Mohana K. Rajpalke • \\ Basanta Roul • Thirumaleshwara N. Bhat • \\ S. B. Krupanidhi
}

Received: 30 October 2012/Accepted: 6 November 2012/Published online: 16 November 2012

(c) The Author(s) 2012. This article is published with open access at Springerlink.com

\begin{abstract}
InN nanorods (NRs) were grown on $\mathrm{Si}(111)$ substrate by plasma-assisted molecular beam epitaxy. The growth of InN NRs has been demonstrated using an electron-beam evaporated ( $\sim 2 \mathrm{~nm}$ ) Au layer prior to the initiation of growth. The structure and morphology of as deposited $\mathrm{Au}$ film, annealed at $600{ }^{\circ} \mathrm{C}$, and InN NRs were investigated using $\mathrm{X}$-ray photoelectron spectroscopy and scanning electron microscopy. Chemical characterization was performed with energy dispersive X-ray analysis. Single-crystalline wurtzite structure of InN NRs is verified by transmission electron microscopy. The formation process of NRs is investigated and a qualitative mechanism is proposed.
\end{abstract}

Keywords InN $\cdot$ Nanostructures $\cdot$ MBE

\section{Introduction}

Group III nitrides represent a material class with promising electronic and optical properties (Nakamura 1998). Among these, InN possesses the lowest effective mass, the highest mobility, narrow band gap $E_{\mathrm{g}}$ of $0.7-0.9 \mathrm{eV}$ and the highest saturation velocity (Wu et al. 2002; Goiran et al.

M. Kumar · M. K. Rajpalke · B. Roul - T. N. Bhat .

S. B. Krupanidhi

Materials Research Centre, Indian Institute of Science,

Bangalore 560012, India

M. Kumar $(\bowtie) \cdot$ B. Roul

Central Research Laboratory, Bharat Electronics,

Bangalore 560013, India

e-mail: mkchahar@mrc.iisc.ernet.in
2010; Kumar et al. 2011) which makes it an attractive material for several applications such as solar cells, terahertz emitters, detectors, ion sensing and field emission (Yang et al. 2000; Bellotti et al. 1999; Chang et al. 2005; Lu et al. 2008; Wang et al. 2008). In recent years, due to distinctive properties and potentials of one dimensional (1D) structure (Fang et al. 2008; 2010) various kinds of InN nanostructures have been grown such as nanowires (NWs), nanotubes (NTs) and nanorods (NRs) by chemical vapor deposition (CVD) (Chang and Hong 2009), metalorganic chemical vapor deposition (MOCVD) (Chen et al. 2009), hydride metalorganic vapor phase epitaxy (H-MOVPE) (Park et al. 2007) and plasma-assisted molecular beam epitaxy (PAMBE) (Stoica et al. 2006). The nitrogen source for the growth of $\mathrm{InN} 1 \mathrm{D}$ structures is usually generated from the decomposition of ammonia at a relatively high temperature $\left(>500{ }^{\circ} \mathrm{C}\right)$ for enough reactivity. However, since InN has low decomposition temperature $\left(500-600{ }^{\circ} \mathrm{C}\right)$ and high vapor pressure above $500{ }^{\circ} \mathrm{C}$, the process window for the growth of InN 1D structures has been very narrow. On the other hand, PAMBE uses reactive nitrogen plasma to replace ammonia as the nitrogen source, and it does not require high growth temperature. To date, there are already several publications on the growth of InN 1D structures with or without catalyst on different substrates such as $\mathrm{Si}$, sapphire, $\mathrm{SiC}$ and GaAs. Many researchers have used $\mathrm{Au}$ catalyst to grow the $\mathrm{InN} 1 \mathrm{D}$ structures (Chang and Hong 2009) by different growth techniques. Here, we report the growth mechanism of InN NRs by PAMBE and the impact of Au layer on InN NRs growth. A systemic study of each growth steps are investigated using X-ray photoelectron spectroscopy (XPS) and scanning electron microscopy (SEM). The formation process of InN NRs is investigated and a qualitative mechanism is proposed. 

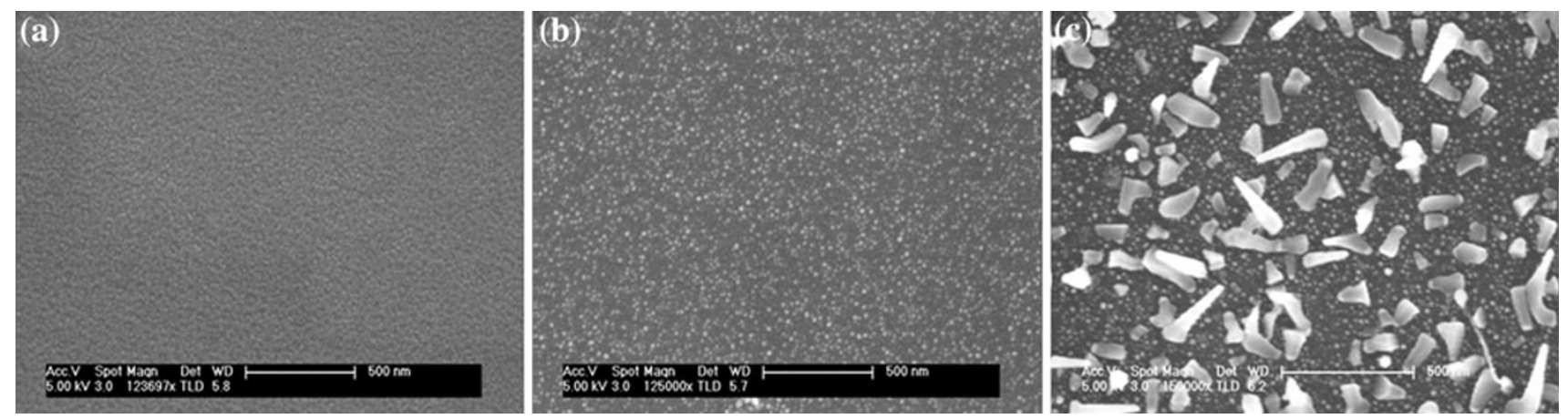

Fig. 1 FESEM images of a as deposited Au film, b annealed Au film at $600{ }^{\circ} \mathrm{C}$ and $\mathbf{c}$ InN NRs
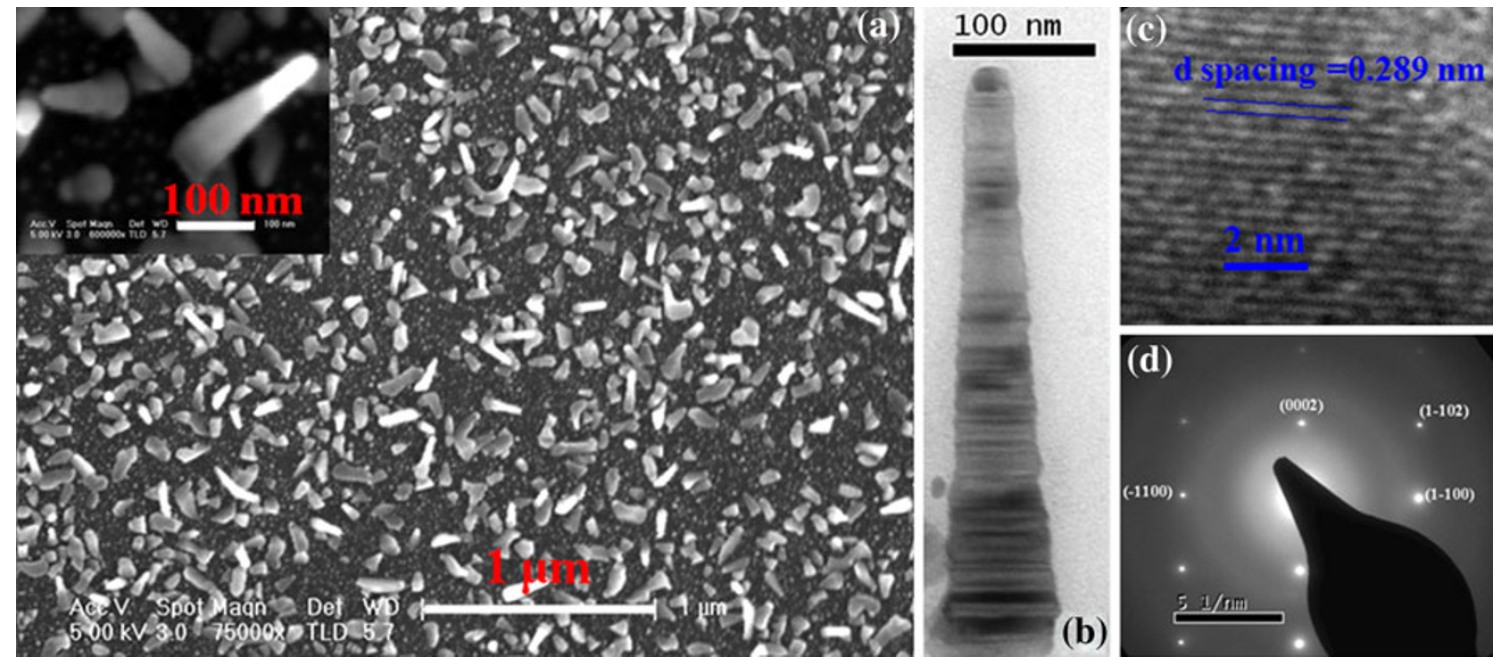

(b)

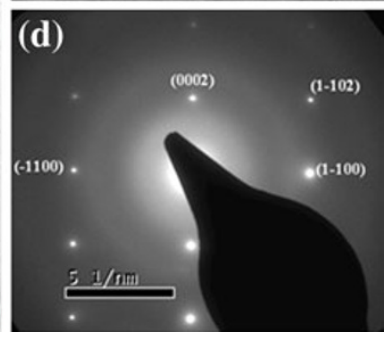

Fig. 2 a A typical FESEM image of InN NRs at different magnifications, b TEM image, c HRTEM and d SAED images of single InN NR

\section{Experimental details}

The growth system used in this study was a PAMBE system (OMICRON) equipped with a radio frequency (RF) plasma source. The base pressure in the system was below $1 \times 10^{-10}$ mbar. The $\mathrm{n}-\mathrm{Si}(111)$ substrates were chemically cleaned followed by dipping in $5 \% \mathrm{HF}$ to remove the surface oxide, and Au layer of $\sim 2 \mathrm{~nm}$ was deposited using electron beam evaporation. The Au film was annealed at $600{ }^{\circ} \mathrm{C}$ for $10 \mathrm{~min}$. Further, the substrate temperature was decreased to $500{ }^{\circ} \mathrm{C}$ to fabricate the NRs. The duration of NR growth was kept for $2 \mathrm{~h}$. The general set of growth conditions include indium beam equivalent pressure, nitrogen flow rate and RF-plasma power, which were kept at $4.6 \times 10^{-8}$ mbar, $1 \mathrm{SCCM}$ and $400 \mathrm{~W}$, respectively. Nitrogen pressure was maintained $5.8 \times 10^{-5}$ mbar during the growth. The structure and morphology of as deposited $\mathrm{Au}$ film, annealed at $600{ }^{\circ} \mathrm{C}$ and InN NRs were investigated using XPS and SEM. The structural evaluation of the as-grown NRs was carried out by transmission electron microscopy (TEM).

\section{Results and discussion}

Figure 1a-c shows the field emission scanning electron microscopy (FESEM) of as deposited Au film, annealed $\mathrm{Au}$ film at $600{ }^{\circ} \mathrm{C}$ and InN NRs, respectively. From the figure it can be seen that the Au-deposited film is smooth and uniformly deposited on the Si substrate. After annealing at $600{ }^{\circ} \mathrm{C}$ for $10 \mathrm{~min}$, it is converted into the dots, and the sizes of these dots are in the range of $15-25 \mathrm{~nm}$. The $\mathrm{InN}$ NRs are randomly oriented and uniformly grown over the entire substrate. The length of these NRs is found in the range of 200-350 nm with a base average diameter of $\sim 42 \mathrm{~nm}$, narrowing to $\sim 18 \mathrm{~nm}$ at the tip. Figure $2 \mathrm{a}$ shows a typical FESEM image of InN NRs at different magnifications and it reveals the absence of $\mathrm{Au}$ on the tip of InN NRs. From the FESEM images, it can be clearly seen, that the Au dots are distributed on the Si substrate in between the NRs. Figure $2 b-d$ represents typical transmission electron micrographs, high resolution TEM (HRTEM) and selected area electron diffraction (SAED) images of single InN NR, respectively. The HRTEM was 
Fig. 3 a The distribution of $\mathrm{Si}$, $\mathrm{In}, \mathrm{Au}$ and $\mathrm{N}$ elements, b-f secondary electron image, $\mathrm{Si}, \mathrm{In}, \mathrm{Au}$ and $\mathrm{N}$ element EDX maps, respectively, $\mathbf{g}$ EDX spectra
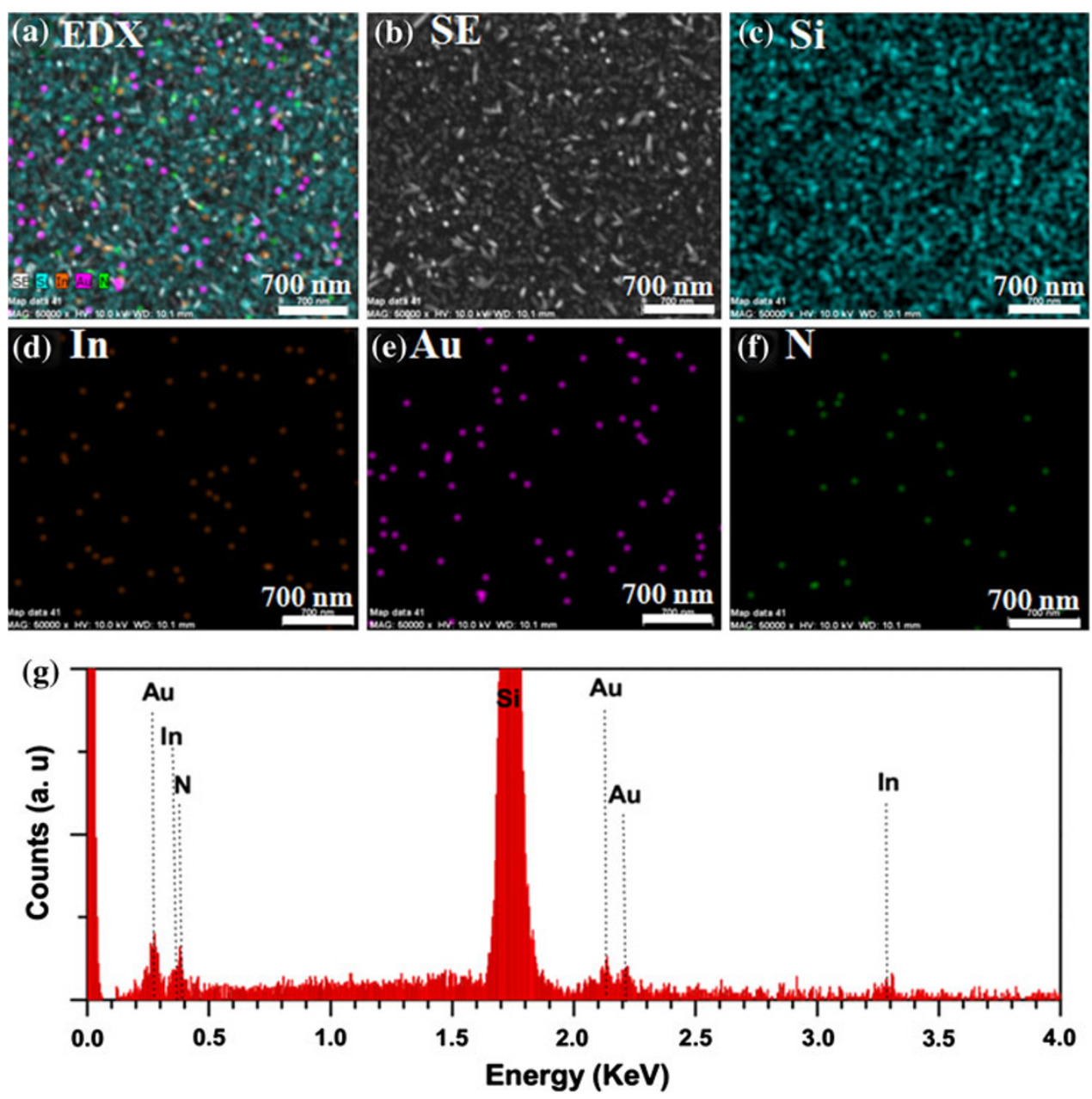

taken on the tip of the NR and the interplanar spacing, as observed from the fringe pattern of the HRTEM image, is $0.289 \mathrm{~nm}$ which corresponds to the (0002) lattice spacing of InN (Chao et al. 2006). The SAED pattern shows clearly the visible bright spots establishing the single-crystalline nature of NRs. These data clearly demonstrate that the asgrown NRs are fairly single-crystalline, and are crystallized hexagonally along the [0001] direction with uniform geometry. There is a slight contrast on the top of NR due to the thickness difference, which is also confirmed by HRTEM. The absence of $\mathrm{Au}$ on the tip of InN NR also supports the FESEM results.

Chemical characterization in the SEM is performed nondestructively with energy dispersive X-ray analysis (EDX) and shown in Fig. 3. Figure 3 a shows the distribution of $\mathrm{Si}$, In, $\mathrm{Au}$ and $\mathrm{N}$ elements and Fig. 3b-f show secondary electron image, $\mathrm{Si}, \mathrm{In}, \mathrm{Au}$ and $\mathrm{N}$ element EDX maps, respectively. Figure $3 g$ shows EDX spectra and it reveals the presence of $\mathrm{Si}, \mathrm{Au}$, In and $\mathrm{N}$ elements. Figure $4 \mathrm{a}$ shows the XPS spectra of the Si $2 p$ of clean $\mathrm{Si}(111)$ substrate, after a $\sim 2 \mathrm{~nm}$ Au deposition on a clean Si(111) substrate, annealed at $600{ }^{\circ} \mathrm{C}$ and InN NRs. Upon Au deposition, core level shifts are observed. After Au deposition, annealed at $600{ }^{\circ} \mathrm{C}$ and InN NRs samples show a shift in the Si 2 p with respect to clean $\mathrm{Si}(111)$ sample about $0.14,0.24$ and $0.26 \mathrm{eV}$, respectively, towards lower binding energy (BE) due to band bending in accordance with the literature (Molodsov et al. 1991; Santoni et al. 2006). Figure 4b shows the evolution of $\mathrm{Au} 4 \mathrm{f}$ core level XPS spectra of $\mathrm{Au}$ foil, after a $\sim 2 \mathrm{~nm}$ Au deposition on a clean $\mathrm{Si}(111)$ substrate, annealed at $600{ }^{\circ} \mathrm{C}$ and InN NRs. The Au 4 f core levels show a shift to higher BE by about 0.21 and $0.69 \mathrm{eV}$ for $\sim 2 \mathrm{~nm} \mathrm{Au}$ deposited and annealed at $600{ }^{\circ} \mathrm{C}$ samples, respectively, which indicates the formation of a $\mathrm{Si}-\mathrm{Au}$ alloy. The corresponding Au-Si (gold silicide) shift of the $\mathrm{Si} 2 \mathrm{p}$ level, expected at about $0.3 \mathrm{eV}$ on the higher BE side, (Santoni et al. 2006; Yeh et al. 1993) is not observed. Peak fitting analysis of the $\mathrm{Si} 2 \mathrm{p}$ core level did not show the presence of a clear $\mathrm{Si}-\mathrm{Au}$ component. On the other hand, the best fit of the back ground subtracted $\mathrm{Au} 4 \mathrm{f}_{7 / 2}$ core level indicated the presence of a small metallic Au component. These results show that the annealed Au sample surface consists of an Au metal on top of the surface, below Au metal a reacted $\mathrm{Au}-\mathrm{Si}$ layer and a bulk $\mathrm{Si}$ substrate at 
Fig. 4 The XPS spectra of a Si 2p, b Au 4f, c In 3d and d N 1s
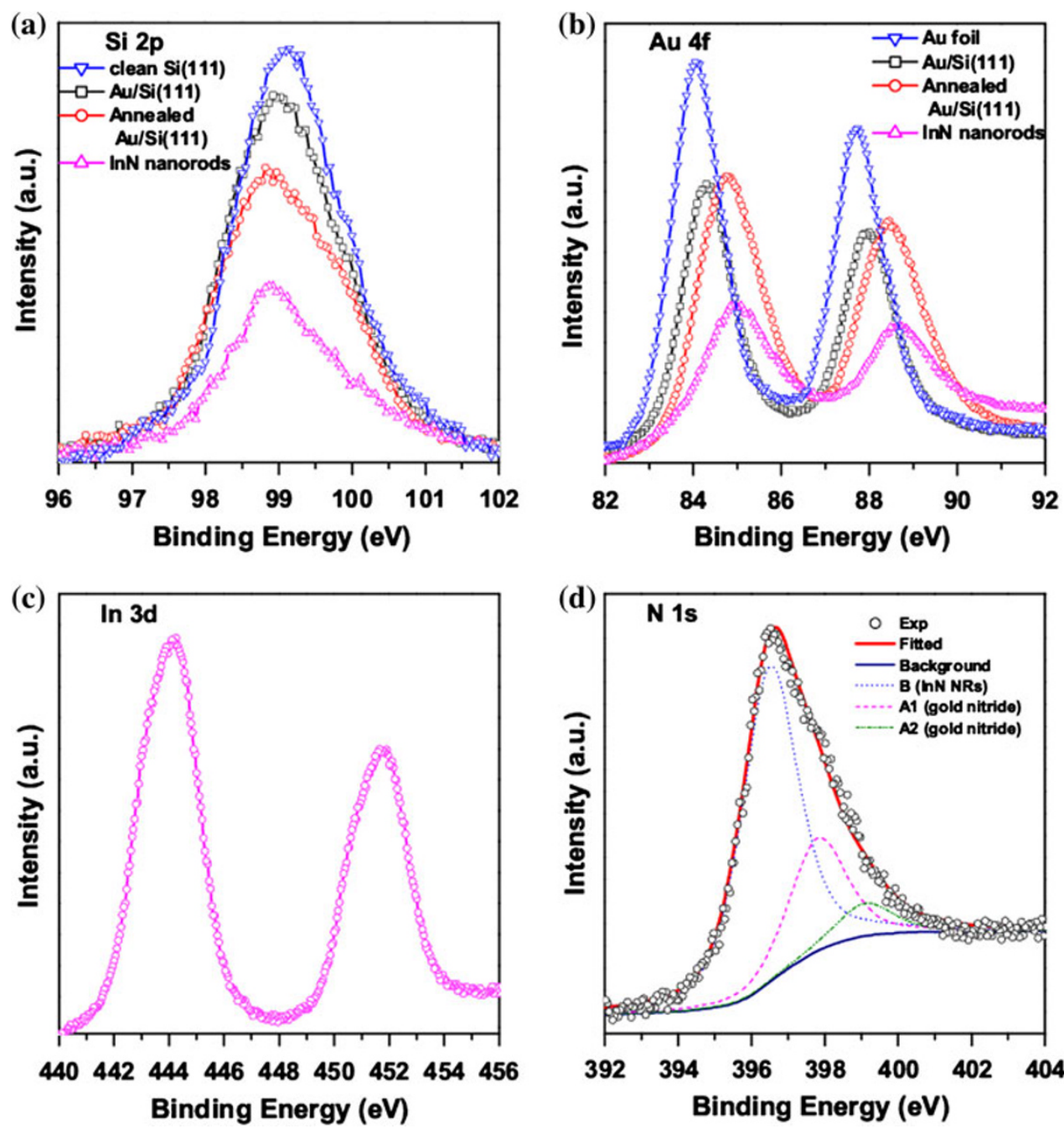

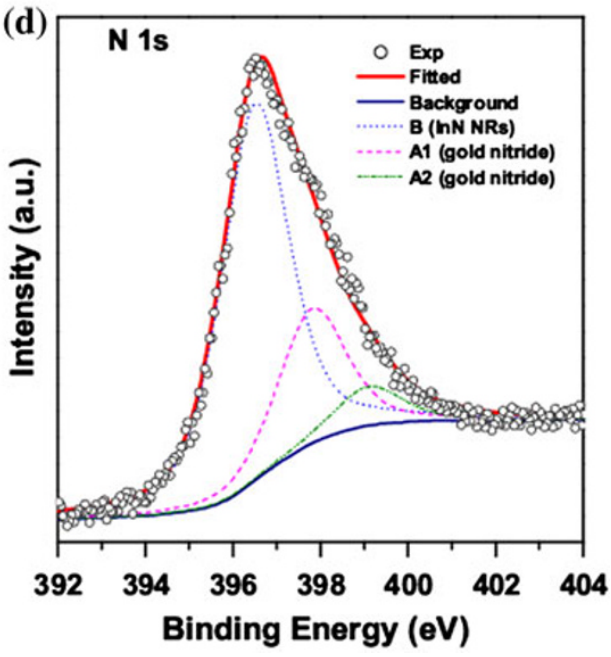

bottom. Further, annealing at $600{ }^{\circ} \mathrm{C}$ does not lead to a fully reacted $\mathrm{Au}-\mathrm{Si}$ overlayer. These results are similar to the data reported in the literature for the $\mathrm{Au} / \mathrm{Si}(111)$ surface (Yeh et al. 1993). Figure 4c shows that the In $3 d$ core is spin-orbit split to the $3 \mathrm{~d}_{5 / 2}$ at $444.11 \mathrm{eV}$ and $3 \mathrm{~d}_{3 / 2}$ peak at $451.59 \mathrm{eV}$, and these results are close to the reported values of InN quantum dots (Kumar et al. 2010). Figure 4d shows the N1s core XPS spectra and two distinct chemical states of nitrogen are observed. Peaks $A 1$ and $A 2$ are attributed to the formation of two gold nitride phases (Siller et al. 2005), while peak $B$ is associated with InN (Kumar et al. 2010). The $\mathrm{Au} 4 \mathrm{f}$ core levels show a shift to higher $\mathrm{BE}$ by about $0.92 \mathrm{eV}$ for InN NRs sample, which also indicates the formation of gold nitride phase (Zhao et al. 2007).

A schematic diagram of the growth mechanism of $\mathrm{InN}$ NRs based on above characterization is proposed and shown in Fig. 5. After annealing of Au film at $600{ }^{\circ} \mathrm{C}$ for $10 \mathrm{~min}$, it is converted into dots and consists of a reacted $\mathrm{Au}-\mathrm{Si}$ (gold silicide) layer between Au metal layer on top and the bulk Si underneath. Further, we have opened the
In and nitrogen plasma source simultaneously to grow the InN, so the reactive nitrogen plasma is also converting the $\mathrm{Au}$ into gold nitride and gold nitride is not acting as a catalyst in PAMBE system. The InN NRs could be formed by the formation of small-sized InN seed particles first in between the gold dots or on gold dots and then growth of nanorods from the seeds.

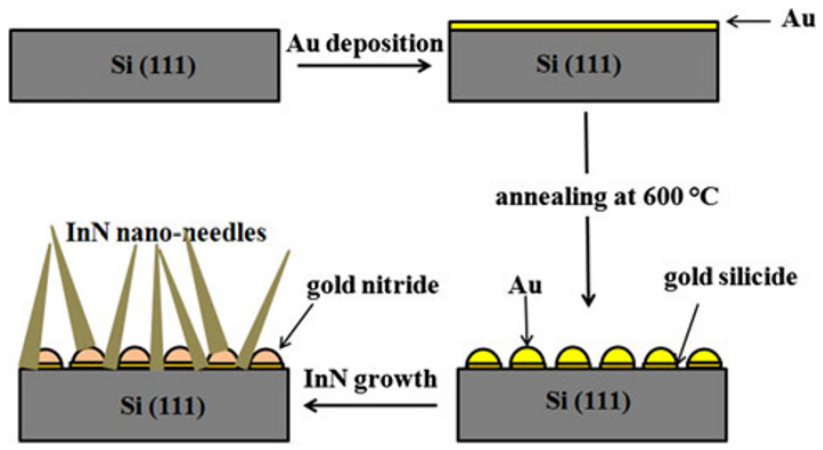

Fig. 5 Schematic diagram of InN NRs growth mechanisms 


\section{Conclusion}

In conclusion, the InN NRs were grown on $\mathrm{Si}(111)$ substrate by PAMBE using $\sim 2 \mathrm{~nm}$ Au film prior to the initiation of growth. The structure and morphology of as deposited Au film, annealed at $600{ }^{\circ} \mathrm{C}$, and InN NRs were investigated using XPS and FESEM. Chemical characterization of InN NRs were performed EDX. It is verified by TEM that the grown NRs are single-crystalline. The formation process of NRs is investigated and a qualitative mechanism is proposed. In the PAMBE, gold is converted into gold nitride which is not acting as a catalyst in PAMBE system.

Open Access This article is distributed under the terms of the Creative Commons Attribution License which permits any use, distribution, and reproduction in any medium, provided the original author(s) and the source are credited.

\section{References}

Bellotti EB, Doshi K, Brennan KF, Albrecht JD, Ruden PP (1999) Ensemble Monte Carlo study of electron transport in wurtzite InN. J Appl Phys 85:916-923

Chang YK, Hong FC (2009) Synthesis and characterization of indium nitride nanowires by plasma-assisted chemical vapor deposition. Mater Lett 63:1855-1858

Chang CY, Chi GC, Wang WM, Chen LC, Chen KH, Ren F, Pearton S (2005) Transport properties of InN nanowires. Appl Phys Lett 87:93112-93114

Chao CK, Chyi JI, Hsiao CN, Kei CC, Kuo SY, Chang HS, Hsu TM (2006) Catalyst-free growth of indium nitride nanorods by chemical-beam epitaxy. Appl Phys Lett 88:233111-233113

Chen RS, Yang TH, Chen HY, Chen LC, Chen KH, Yang YJ, Su CH, Lin CR et al (2009) High-gain photoconductivity in semiconducting InN nanowires. Appl Phys Lett 95:162112-162114

Fang Z, Zhang X, Liu D, Zhu X (2008) Excitation of dielectric-loaded surface plasmon polariton observed by using near-field optical microscopy. Appl Phys Lett 93:073306-073308

Fang Z, Huang S, Lu Y, Pan A, Lin F, Zhu X (2010) Colorchangeable properties of plasmonic waveguide based on Sedoped CdS nanoribbons. Phys Rev B 82:85403-85409

Goiran M, Millot M, Poumirol JM, Gherasoiu I, Walukiewicz W, Leotin J (2010) Electron cyclotron effective mass in indium nitride. Appl Phys Lett 96:52117-52119
Kumar M, Roul B, Bhat TN, Rajpalke MK, Sinha N, Kalghatgi AT, Krupanidhi SB et al (2010) Droplet epitaxy of InN quantum dots on $\mathrm{Si}(111)$ by RF plasma-assisted molecular beam epitaxy. Adv Sci Lett 3:379-384

Kumar M, Roul B, Shetty A, Rajpalke MK, Bhat TN, Kalghatgi AT, Krupanidhi SB (2011) Temperature dependent transport studies in InN quantum dots grown by droplet epitaxy on silicon nitride/ Si substrate. Appl Phys Lett 99:153114-153116

Lu YS, Ho CL, Yeh JA, Lin HW, Gwo S (2008) Anion detection using ultrathin InN ion selective field effect transistors. Appl Phys Lett 92:212102-212104

Molodsov SL, Laubshat C, Kaindl G, Shikin AM, Adamchuk VK (1991) Formation and chemical structure of the $\mathrm{Au} / \mathrm{Si}(111)$ interface. Phys Rev B 44:8850-8857

Nakamura S (1998) The roles of structural imperfections in InGaNbased blue light-emitting diodes and laser diodes. Science 281:956-961

Park HJ, Kryliouk O, Anderson T, Khokhlov D, Burbaev T (2007) Growth of InN films and nanorods by H-MOVPE. Physica E 37:142-147

Santoni A, Villacorta FJ, Rufoloni A, Mancini A (2006) Growth of Au-catalysed Si nanowires by low pressure chemical vapour deposition on $\mathrm{Si}(100)$ and amorphous $\mathrm{Si}$ surfaces. J Phys: Condens Matter 18:10853-10859

Siller L, Peltekis N, Krishnamurthy S, Chao Y, Bull SJ, Hunt MRC (2005) Gold film with gold nitride-A conductor but harder than gold. Appl Phys Lett 86:221912-221914

Stoica T, Meijers R, Calarco R, Richter T, Luth H (2006) MBE growth optimization of InN nanowires. J Crystal Growth 290:241-247

Wang KR, Lin SJ, Tu LW, Chen M, Chen QY, Chen TH, Chen ML, Seo HW, Tai NH, Chang SC, Lo I, Wang DP, Chu WK (2008) InN nanotips as excellent field emitters. Appl Phys Lett 92:123105-123107

Wu J, Walukiewicz W, Yu KM, Ager III JW, Haller EE, Lu H, Schaff WJ, Saito Y, Nanishi Y (2002) Unusual properties of the fundamental band gap of InN. Appl Phys Lett 80:3967-3969

Yang HC, Kuo PF, Lin TY, Chen YF, Chen KH, Chen LC, Chyi JI (2000) Mechanism of luminescence in InGaN/GaN multiple quantum wells. Appl Phys Lett 76:3712-3714

Yeh JJ, Hwang J, Bertness K, Friedman DJ, Cao R, Lindau I (1993) Growth of the room temperature $\mathrm{Au} / \mathrm{Si}(111)-7 \times 7$ interface. Phys Rev Lett 70:3768-3771

Zhao L, Siu ACL, Petrus JA, He Z, Leung KT (2007) Interfacial bonding of gold nanoparticles on a H-terminated $\mathrm{Si}(100)$ substrate obtained by electro- and electroless deposition. J Am Chem Soc 129:5730-5734 